\title{
Individuals with special needs and their families' oral health-related quality of life
}

\author{
Viviane $\mathrm{CANCIO}^{(\mathrm{a})}$ \\ Khawana FAKER ${ }^{(a)}$ \\ Cristiane Baccin BENDO(b) \\ Saul Martins PAIVA(b) \\ Mônica Almeida TOSTES(a)
}

(a) Universidade Federal Fluminense - UFF, School of Dentistry, Department of Pediatric Dentistry, Niterói, RJ, Brazil.

(b) Universidade Federal de Minas Gerais UFMG, School of Dentistry, Department of Pediatric Dentistry and Orthodontics, Belo Horizonte, MG, Brazil.

Declaration of Interests: The authors certify that they have no commercial or associative interest that represents a conflict of interest in connection with the manuscript.

\section{Corresponding Author:}

Viviane Cancio

E-mail:vicancio@ig.com.br

Submitted: October 30, 2017

Accepted for publication: March 03, 2018

Last revision: Apr 04, 2018

\begin{abstract}
To evaluate the impact of dental caries among Brazilian individuals with special health care needs (SHCN) on their families' oral health-related quality of life (OHRQoL). A cross-sectional study was carried out with a population-based sample of 227 subjects who were enrolled from the ACOLHER-PNE project conducted at the Fluminense Federal University. Parents/caregivers answered the Brazilian version of the 14-item Family Impact Scale (B-FIS) to assess the impact on family's quality of life (QoL). The main independent variable was dental caries experience, diagnosed according to the World Health Organization (WHO) criteria. The DMFT/dmft score was categorized into $0=$ caries free; $1-2=10 w ; 3-4=$ moderate; and $\geq 5$ = high experience. Mother's schooling, age, sex, SHCN conditions, and socioeconomic factors were the other independent variables. QoL was measured through FIS domains and total score. Statistical analyses was performed using the Kruskal Wallis and Mann Whitney $\mathrm{U}$ tests and Poisson regression $(\mathrm{p}<0.05)$. The impact values observed in moderate and high caries experience were significantly higher than those found in subjects without caries and low level of parental emotions. Parents' years of schooling showed more impact on total score and on parental emotions. Older subjects showed significantly higher impact on total score and in all domains. The multivariate model demonstrated that families of older subjects ( $>8$ years old) experience a higher impact level compared to younger subjects (PR: 2.43; 95\%CI: 1.80-3.29, $\mathrm{p}=0.001$ ). High caries experience and other socioeconomic factors were not associated with a greater negative impact on parents' QoL.
\end{abstract}

Keywords: Dental Caries; Prevalence; Quality of Life.

\section{Introduction}

Individuals with special health care needs ( $\mathrm{SHCN}$ ) may have pathologies of many origins, including congenital, genetic, infectious, physical, and toxic, or caused by poor diet and drug interactions during pregnancy, possibly resulting in speech, movement, and/or sensory disorders. Such conditions cause medical and dental problems that compromise their quality of life, and these oral conditions may have an impact on family's quality of life (QoL). ${ }^{1,2,3}$ 
Dental caries are more prevalent in older SHCN individuals and can be associated with a negative impact on oral health-related quality of life (OHRQoL) of children and adolescents. ${ }^{4,5,6,7}$ Although families of children with disabilities or other special needs have the same need for child care than do other families, SHCN children have higher difficulty moving and performing or receiving an effective oral hygiene ${ }^{5,7,8}$ than healthy children. ${ }^{1}$ This could lead to high caries severity and poorer OHRQoL., ${ }^{4.7}$ Limited access to dental care, high sugar intake, never going to the dentist, poor oral health, low health literacy, and limited use of fluoridated water are thought to be key factors for these health problems. ${ }^{1,7,8}$

The concept of health-related quality of life (HRQoL) concerns the ability to perform daily activities and considers subjective aspects such as happiness, social well-being, and emotional well-being. Likewise, OHRQoL concerns the impact oral health or disease causes on an individual's daily functioning, well-being, and quality of life. ${ }^{9,10,11}$ The Family Impact Scale (FIS) is an instrument developed to determine the impact of children's oral and orofacial conditions on family's OHRQoL. ${ }^{12}$ The B-FIS is a validated instrument that measures how oral condition can have a negative impact on family's quality of life. ${ }^{13,14}$ However, the method has been poorly used in HSCN subjects. ${ }^{15,16}$

The Brazilian Institute of Geography and Statistics (IBGE) data show that $6.2 \%$ of the Brazilian population has some type of disability (auditory, visual, physical, and/or intellectual). ${ }^{17}$ Thus, multiple factors have to be considered when investigating OHRQoL in SHCN subjects. ${ }^{1,2,3}$ Previous OHRQoL studies described that severity of dental caries, communication ability, limitations due to physical impairment, socioeconomic status, and medical conditions can be associated with a negative impact on the OHRQoL of children and adolescents with SHCN and of their families. ${ }^{5,6,7,15,16,18}$ Furthermore, as children with disabilities reach adulthood, oral health care may be restricted by lack of adequate access to private or public health insurance and lack of preventive and timely therapeutic care. ${ }^{1}$ Therefore, lack of care may increase the need for costly care and exacerbate oral and systemic health problems. ${ }^{1}$ Several studies have evaluated the impact of oral conditions only on children and adolescents. ${ }^{5,6,7,15,16,18}$ Thus, the impact of oral diseases on children, adolescents, and adults with $\mathrm{SHCN}$ remains unclear.

Accordingly, the aim of the present study was to evaluate the impact of dental caries in children and adults with SHCN on the OHRQoL of their families, as well as the influence of socioeconomic factors on their perception of quality of life.

\section{Methodology}

\section{Ethical approval}

A written informed consent was obtained from the parents or legal guardians of all participants, and all procedures were clearly explained to the parents/ guardians and participants before their inclusion in the study. The study was conducted according to Brazilian Resolution no. 466 (2012) principles for medical research involving human subjects. The study protocol was approved by the Fluminense Federal University's Human Research Ethics Committee (439.086/2013).

\section{Study design}

A convenience sample was selected for this crosssectional study. It included children and adults with SHCN from the ACOLHER-PNE project conducted at the Fluminense Federal University's Dental School. This population-based study was conducted from September to December 2016 with subjects aged 3 to 35 years in the city of Niterói, Rio de Janeiro, Brazil. Subjects unable to cooperate due to their medical conditions and those children whose parents refused to give their consent were not included in the study (three subjects). The final sample comprised 227 subjects. Subjects whose legal guardians consented to their participation, and those who gave their assent were eligible for the study.

\section{Calibration of the examiners}

The research team was made up of two dentists (VC-examiner 1 and KF-examiner 2) who had participated in a training and calibration exercise. ${ }^{3}$ The calibration exercise consisted of theoretical and clinical steps. The theoretical step involved a 
discussion on the diagnostic criteria for the Decayed, Missing, and Filled Teeth Index (dmft for primary teeth/DMFT for permanent teeth). These steps were reviewed and discussed by the examiners and by an experienced dentist who was considered gold standard. The clinical step was conducted with 40 subjects aged 8 and 9 years on two occasions with a two-week interval between examinations. These subjects were not included in the main sample. The intra-examiner and inter-examiner Kappa coefficients were 0.87 to 0.96 and 0.89 to 0.92 , for examiners 1 and 2 , respectively.

\section{Data collection}

The parents self-completed the B-FIS and the sociodemographic questionnaire in a waiting room, and returned them to the research team without any identification. A clinical oral examination of the clean and dry teeth was performed by two examiners in a dental unit with the aid of a dental unit light. Parents were also invited to answer a questionnaire on their socioeconomic status measured in terms of the Brazilian minimum wage - BMW, a standard for this type of assessment, which corresponded to approximately 273.17 US dollars/ month at the time of data collection.

The intraoral exam was performed on each patient using a plane mouth mirror, (Duflex, S.S.White LTDA, Rio de Janeiro, Brazil) and a CPI probe (Duflex, S.S.White LTDA, Rio de Janeiro, Brazil), following the World Health Organization (WHO) recommendations for oral epidemiological surveys. ${ }^{19}$ The DMFT/dmft index was evaluated (decay, $\mathrm{m} / \mathrm{M}=$ missing, $\mathrm{f}$ / $\mathrm{F}=$ filling, $\mathrm{t} / \mathrm{T}=$ teeth, $\mathrm{d} / \mathrm{D}=\mathrm{dmft} / \mathrm{DMFT}$ ). The $\mathrm{D}$ component includes all teeth with caries (code 1) or filled, with caries (code 2). The M component comprises teeth (code 4) in subjects younger than 30 years and in subjects 30 years and older (code 5), i.e. missing teeth due to caries or for any other reason. The $\mathrm{F}$ component includes teeth classified only as code 3 . The basis for DMFT calculations is 32 teeth, i.e., all permanent teeth including wisdom teeth. In the case of primary teeth, the calculation of the $\mathrm{dmft}$ index was similar, i.e., by deriving information from data codes A (sound crown), B (carious crown), C (filled crown, with caries), D (filled crown, with no caries), and $\mathrm{E}$ (missing tooth, due to caries) in the oral health assessment form. ${ }^{19}$

\section{Outcome and Explanatory Variables}

The outcome variable was the impact on OHRQoL obtained from the B-FIS. The FIS was developed as one component of the Child Oral Health Quality of Life Instrument (COHQOL). This instrument was designed to assess the OHRQoL of children aged 6-14 years with oral and orofacial conditions and of their families. ${ }^{12}$ It consists of 14 items divided into four subscales: parental/family activity (PA), parental emotions (PE), family conflict (FC), and financial burden (FB). The global rating has a fivepoint response format raging form 'never $=0$ ' to 'every day or almost every day $=4$ '. Higher scores indicate worse OHRQoL. ${ }^{12}$ The Brazilian version of the FIS (B-FIS) is a reliable and valid questionnaire for assessing the family impact caused by children's oral condition. ${ }^{13,14}$

The main explanatory variable in our study was dental caries experience. To classify the patients based on caries experience, the patients underwent a dental exam in accordance with the $\mathrm{dmft} / \mathrm{DMFT}$ index. ${ }^{19}$ The subjects were categorized as caries-free when $\mathrm{dmft} / \mathrm{DMFT}=0$, low caries experience when $\mathrm{dmft} /$ $\mathrm{DMFT}=1-2 ;$ moderate caries experience when $\mathrm{dmft} /$ $\mathrm{DMFT}=3-4$; and high caries experience when $\mathrm{dmft} /$ DMFT $\geq 5 .{ }^{20}$ Other explanatory variables included sex, patient's age ( $\leq 8$ years, $>8$ years), household income (classified based on the Brazilian minimum wage, which was equivalent to US\$ 273.17 - < 2BMW; and $\geq 2 \mathrm{BMW}),{ }^{21}$ and mother's years of schooling ( $\leq 8$ years, $>8$ years).

SHCN conditions were grouped according to the American Academy of Pediatrics definition of SHCN as follows: syndromes, behavioral disorders, systemic diseases, sensory disorders, physical deficiencies, and mental retardation. ${ }^{1}$

\section{Statistical analysis}

The Statistical Package for the Social Sciences (SPSS for Windows, version 20.0, SPSS Inc., Armonk, NY, USA) was used for data analyses, initially through descriptive statistics. The relative frequency (\%) of all variables was obtained for characterization 
of the sample and of the component items of the B-FIS questionnaire. Multivariate Poisson regression with robust variance was performed to observe the association between overall B-FIS and domains (outcome) with each independent variable. ${ }^{20}$ The variable with $\mathrm{p}<0.05$ (Kruskal Wallis test) was included in the model. Age, caries experience, and mother's years of schooling were considered in the final model for the B-FIS and for each domain. The prevalence ratio (PR) and respective $95 \%$ confidence intervals $(95 \% \mathrm{CI})$ were estimated for the variables included in the final model, at a 5\% significance level. Internal consistency was assessed by computing Cronbach's alpha for the questionnaire and for the categories.

\section{Results}

A total of 227 subjects and their parents or caregivers participated in the study. Most of the questionnaires were answered by mothers $(85.9 \%)$. The patients were classified into six groups: 43 (18.9\%) patients with syndromes, 111 (48.9\%) with behavioral disorders, 5 (2.2\%) with systemic diseases, 33 (14.7\%) with sensory disorders, 34 (14.9\%) with neurological disorders, and $1(0.4 \%)$ with a contagious infection. The mean age of patients was 10.56 years $(\mathrm{SD}=7.34)$. The study group consisted of 153 (67.4\%) males and $74(32.6 \%)$ females. Most of the parents had more than eight years of education (62.1\%) and earned $<2$ BWM (58.1\%). Caries experience was low in 37 $(16.3 \%)$, moderate in 26 (11.5\%), and high in 52 (22.9\%) subjects. One hundred twelve (49.3\%) individuals were caries-free (Table 1).

Table 2 presents the mean and standard deviation (SD) of the overall B-FIS, PA, PE, FC, and FB subscale scores according to independent variables. The impact values observed in moderate and high caries experience were significantly higher than those found in cariesfree subjects and with low level of parenteral emotions $(\mathrm{p}<0.05$; Kruskal Wallis and Mann Whitney tests). Parents' years of schooling showed more impact on total score and on parental emotions. Older subjects showed a significantly higher impact on total score and in all domains when compared to younger subjects ( $p<0.05 ;$ Kruskal Wallis and Mann Whitney tests).
Table 1. Sample characterization and clinical data

\begin{tabular}{|c|c|c|}
\hline Variable & $\mathrm{n}$ & $\%$ \\
\hline Gender & 227 & 100 \\
\hline Male & 153 & 67.4 \\
\hline Female & 74 & 32.6 \\
\hline Years of schooling & 227 & 100 \\
\hline$\leq 8$ & 62 & 27.3 \\
\hline$>8$ & 141 & 62.1 \\
\hline Household income & 203 & 89.4 \\
\hline$<2$ & 118 & 58.1 \\
\hline$\geq 2$ & 85 & 37.4 \\
\hline Age & 227 & 100 \\
\hline$\leq 8$ & 111 & 48.9 \\
\hline$>8$ & 116 & 51.1 \\
\hline Conditions & 227 & 100 \\
\hline Neurological disorder & 34 & 14.9 \\
\hline Behavioral & 111 & 48.9 \\
\hline Syndromes & 43 & 18.9 \\
\hline Sensory & 33 & 14.7 \\
\hline Systemic & 5 & 2.2 \\
\hline Contagious infection & 1 & 0.4 \\
\hline Caries severity & 227 & 100 \\
\hline Caries & 112 & 49.3 \\
\hline Low & 37 & 16.3 \\
\hline Moderate & 26 & 11.5 \\
\hline High & 52 & 22.9 \\
\hline
\end{tabular}

Table 3 shows the frequency distribution of responses according to each item of the B-FIS. The items with greatest frequency on the B-FIS were 'Has your sleep or that of the other parent been disrupted?' (77.5\%), 'Have you or the other parent felt guilty?' $(66 \%)$, 'Have you or the other parent worried that your child will have fewer life opportunities?' (63\%), and 'Have you or the other parent been upset?'(53.7\%).

The results of the multivariate Poisson regression model for the impact of independent variables on the family's quality of life is shown in Table 4. Finally, the multivariate model demonstrated that families of older subjects (aged $>8$ years) experienced a higher impact level compared to younger subjects (PR: 2.43; 95\%CI: 1.80-3.29, $\mathrm{p}=0.001)$. Caries experience was not associated with a greater negative impact on parents' QoL. Cronbach's alpha was 0.93 for the questionnaire as a whole. 
Table 2. Mean (SD) and subscale scores according to independent variables $(\mathrm{N}=227)$

\begin{tabular}{|c|c|c|c|c|c|}
\hline \multirow[t]{2}{*}{ Variable } & Overall B-FIS & $\begin{array}{c}\text { Parental/family } \\
\text { activity }\end{array}$ & Parental emotions & Family conflict & Financial burden \\
\hline & Mean (SD) & Mean (SD) & Mean (SD) & Mean (SD) & Mean (SD) \\
\hline \multicolumn{6}{|l|}{ Gender } \\
\hline Male & $8.93(10.76)$ & $3.22(4.05)$ & $3.44(3.79)$ & $1.75(3.44)$ & $0.48(1.08)$ \\
\hline Female & $8.32(8.37)$ & 3.15 (3.39) & $3.12(3.25)$ & $1.88(3.47)$ & $0.47(0.86)$ \\
\hline \multicolumn{6}{|l|}{ Parents'years of schooling } \\
\hline$\leq 8$ years & $6.47(9.82)^{a}$ & $2.55(3.71)$ & $2.38(3.28)^{a}$ & $1.11(3.20)$ & $0.43(0.99)$ \\
\hline$>8$ years & $9.43(10.03)^{b}$ & $3.40(3.87)$ & $3.64(3.68)^{b}$ & $2.00(3.50)$ & $0.49(1.02)$ \\
\hline \multicolumn{6}{|l|}{ Household income } \\
\hline$<2$ BMW & 8.66 (10.39) & $1.60(3.26)$ & $3.43(3.74)$ & $1.60(3.26)$ & $0.42(0.97)$ \\
\hline$\geq 2 \mathrm{BMW}$ & $7.97(8.80)$ & $2.49(4.46)$ & $2.70(2.92)$ & $2.49(4.46)$ & $0.54(0.88)$ \\
\hline \multicolumn{6}{|l|}{ Age } \\
\hline$\leq 8$ years & $5.21(5.78)^{a}$ & $2.07(2.78)^{\circ}$ & $2.24(2.84)^{a}$ & $0.64(1.36)^{\mathrm{a}}$ & $0.25(0.69)^{a}$ \\
\hline$>8$ years & $12.19(11.97)^{b}$ & $4.30(4.40)^{\mathrm{b}}$ & $4.42(3.98)^{b}$ & $2.90(4.37)^{b}$ & $0.69(1.21)^{\mathrm{b}}$ \\
\hline \multicolumn{6}{|l|}{ Conditions } \\
\hline Neurological disorder & $11.24(10.11)$ & $4.03(3.64)$ & $4.15(3.82)$ & $2.29(3.43)$ & $0.76(1.30)$ \\
\hline Behavioral & $9.36(10.93)$ & $3.30(3.87)$ & $3.57(3.78)$ & $2.11(4.07)$ & $0.53(1.05)$ \\
\hline Syndromes & $7.44(9.27)$ & $3.00(4.22)$ & $2.93(3.48)$ & $1.21(2.27)$ & $0.30(0.74)$ \\
\hline Sensory & $6.21(7.18)$ & 2.39 (3.49) & $2.42(2.92)$ & $1.12(2.16)$ & $0.27(0.80)$ \\
\hline Systemic & $0.00(0.00)$ & $0.00(0.00)$ & $0.00(0.00)$ & $0.00(0.00)$ & $0.00(0.00)$ \\
\hline Contagious infection* & $10.00(-)$ & $5.00(-)$ & $5.00(-)$ & $0.00(-)$ & $0.00(-)$ \\
\hline \multicolumn{6}{|l|}{ Caries experience } \\
\hline Caries-free & $8.26(10.34)$ & $3.00(3.83)$ & $2.91(3.51)^{a}$ & $1.85(3.58)$ & $0.51(1.09)$ \\
\hline Low & $6.19(9.57)$ & $2.59(2.42)$ & $2.49(3.07)^{a}$ & $0.86(1.60)$ & $0.24(0.64)$ \\
\hline Moderate & $8.88(7.93)$ & $3.20(3.50)$ & $3.56(3.24)^{a, b}$ & $1.56(5.92)$ & $0.56(1.00)$ \\
\hline High & $11.46(12.15)$ & $4.12(4.72)$ & $4.75(4.06)^{b}$ & $2.12(3.62)$ & $0.46(1.01)$ \\
\hline
\end{tabular}

Values in columns with different superscript letters = statistically significant differences at $p<0.05$; Kruskal-Wallis test and Mann-Whitney test; ${ }^{n} n=1$

Table 3. Percentage distribution of parents' response on the B-FIS $(n=227)$.

\begin{tabular}{|c|c|c|c|c|c|c|}
\hline \multirow[t]{2}{*}{ During the past three months, how often... } & Never & $\begin{array}{l}\text { Once/ } \\
\text { twice }\end{array}$ & Sometimes & Often & $\begin{array}{l}\text { Every day/almost } \\
\text { every day }\end{array}$ & $\begin{array}{l}\text { I do not } \\
\text { know }\end{array}$ \\
\hline & $n(\%)$ & $n(\%)$ & $n(\%)$ & $n(\%)$ & $n(\%)$ & $n(\%)$ \\
\hline \multicolumn{7}{|l|}{ Parental/family activity (PA) } \\
\hline FIS 1 Have you or the other parent taken time off work? & $164(72.2)$ & 18 (7.9) & $34(15)$ & $5(2.2)$ & $2(0.9)$ & $2(0.9)$ \\
\hline $\begin{array}{l}\text { FIS } 2 \text { Has your child required more attention from you or the } \\
\text { other parent? }\end{array}$ & $157(69.9)$ & $9(4.0)$ & $30(13.2)$ & $20(8.8)$ & $7(3.1)$ & $4(1.8)$ \\
\hline $\begin{array}{l}\text { FIS } 3 \text { Have you or the other parent had less time for } \\
\text { yourselves or the other family members? }\end{array}$ & $156(68.7)$ & $9(4.0)$ & $43(18.9)$ & $10(4.4)$ & $4(1.8)$ & $4(1.8)$ \\
\hline FIS 4 Has your sleep or that of the other parent been disrupted? & $148(65.2)$ & $19(8.4)$ & $43(18.9)$ & $12(5.3)$ & $1(0.4)$ & $4(1.8)$ \\
\hline FIS 5 Have family activities been interrupted? & $176(77.5)$ & $15(6.6)$ & $20(8.8)$ & $7(3.1)$ & $3(1.3)$ & $6(2.6)$ \\
\hline \multicolumn{7}{|l|}{ Parental emotions (PE) } \\
\hline FIS 6 Have you or the other parent been upset? & $122(53.7)$ & $18(7.9)$ & 44 (19.4) & $28(12.3)$ & $8(3.5)$ & $6(2.6)$ \\
\hline FIS 7 Have you or the other parent felt guilty? & $151(66.5)$ & $10(4.4)$ & $36(15.9)$ & $17(7.5)$ & $8(3.5)$ & $4(1.8)$ \\
\hline $\begin{array}{l}\text { FIS } 8 \text { Have you or the other parent worried that your child } \\
\text { will have fewer life opportunities? }\end{array}$ & 145 (63.9) & $10(4.4)$ & 36 (15.9) & $22(9.7)$ & $8(3.5)$ & $4(1.8)$ \\
\hline FIS 9 Have you felt uncomfortable in public places? & $171(75)$ & $8(3.5)$ & $34(15)$ & $9(4.0)$ & $3(1.3)$ & $1(0.4)$ \\
\hline \multicolumn{7}{|l|}{ Family conflict (FC) } \\
\hline FIS 10 Has you child argued with you or the other parent? & $192(84.6)$ & $6(2.6)$ & $15(6.6)$ & $4(1.8)$ & $2(0.9)$ & $7(3.1)$ \\
\hline $\begin{array}{l}\text { FIS } 11 \text { Has you child been jealous of you or another } \\
\text { family member? }\end{array}$ & $172(75.8)$ & $4(1.8)$ & $20(8.8)$ & $20(8.8)$ & $1(0.4)$ & $9(4.0)$ \\
\hline $\begin{array}{l}\text { FIS } 12 \text { Has your child's condition caused disagreement or } \\
\text { conflict in the family? }\end{array}$ & $187(82.4)$ & $14(6.2)$ & $15(6.6)$ & $4(1.8)$ & $1(0.4)$ & $5(2.2)$ \\
\hline FIS 13 Has your child blamed you or the other parent? & $199(87.7)$ & $7(3.1)$ & $9.0(4.0)$ & $2(0.9)$ & $9(4.0)$ & $1(0.4)$ \\
\hline \multicolumn{7}{|l|}{ Financial burden (FB) } \\
\hline $\begin{array}{l}\text { FIS } 14 \text { Has your child's condition caused financial } \\
\text { difficulties for your family? }\end{array}$ & $174(76.7)$ & $20(8.8)$ & $19(8.4)$ & $9(4.0)$ & $2(0.9)$ & $3(1.3)$ \\
\hline
\end{tabular}


Table 4. Multivariate Poisson regression model for association between independent variables $(p<0.05)$ and the overall B-FIS and specific subscales.

\begin{tabular}{|c|c|c|c|c|c|c|c|c|c|c|}
\hline \multirow{2}{*}{ Variable } & \multicolumn{2}{|c|}{ Overall B-FIS } & \multicolumn{2}{|c|}{ Parental/family activity } & \multicolumn{2}{|c|}{ Parental emotions } & \multicolumn{2}{|c|}{ Family conflict } & \multicolumn{2}{|c|}{ Financial burden } \\
\hline & $\mathrm{PR}(95 \% \mathrm{Cl})$ & $\mathrm{p}$-value & $\mathrm{PR}(95 \% \mathrm{Cl})$ & $p$-value & $\mathrm{PR}(95 \% \mathrm{Cl})$ & $p$-value & $\mathrm{PR}(95 \% \mathrm{Cl})$ & $p$-value & $\mathrm{PR}(95 \% \mathrm{Cl})$ & $p$-value \\
\hline \multicolumn{11}{|c|}{ Years of schooling } \\
\hline$\leq 8$ years & 1 & & 1 & & 1 & & 1 & & 1 & \\
\hline$>8$ years & $\begin{array}{c}1.22 \\
(0.85-1.76)\end{array}$ & 0.287 & $\begin{array}{c}1.14 \\
(0.79-1.53)\end{array}$ & 0.465 & $\begin{array}{c}1.27 \\
(0.89-1.80)\end{array}$ & 0.176 & $\begin{array}{c}1.38 \\
(0.71-2.71)\end{array}$ & 0.338 & $\begin{array}{c}1.02 \\
(0.53-1.95)\end{array}$ & 0.945 \\
\hline \multicolumn{11}{|l|}{ Age } \\
\hline$\leq 8$ years & 1 & & 1 & & 1 & & 1 & & 1 & \\
\hline$>8$ years & $\begin{array}{c}2.43 \\
(1.80-3.29)\end{array}$ & $<0.001$ & $\begin{array}{c}2.23 \\
(1.61-3.10)\end{array}$ & $<0.001$ & $\begin{array}{c}1.94 \\
(1.41-2.67)\end{array}$ & $<0.001$ & $\begin{array}{c}4.70 \\
(2.77-7.97)\end{array}$ & $<0.001$ & $\begin{array}{c}3.26 \\
(1.74-6.09)\end{array}$ & $<0.001$ \\
\hline \multicolumn{11}{|c|}{ Caries experience } \\
\hline Caries-free & 1 & & 1 & & 1 & & 1 & & 1 & \\
\hline Low & $\begin{array}{c}0.64 \\
(0.42-0.98)\end{array}$ & 0.041 & $\begin{array}{c}0.83 \\
(0.55-1.26)\end{array}$ & 0.201 & $\begin{array}{c}0.73 \\
(0.44-1.21)\end{array}$ & 0.225 & $\begin{array}{c}0.30 \\
(0.13-0.74)\end{array}$ & 0.005 & $\begin{array}{c}0.34 \\
(0.13-0.88)\end{array}$ & 0.026 \\
\hline Moderate & $\begin{array}{c}0.87 \\
(0.56-1.37)\end{array}$ & 0.563 & $\begin{array}{c}0.92 \\
(0.53-1.61)\end{array}$ & 0.358 & $\begin{array}{c}1.05 \\
(0.68-1.62)\end{array}$ & 0.823 & $\begin{array}{c}0.49 \\
(0.23-1.05)\end{array}$ & 0.069 & $\begin{array}{c}1.10 \\
(0.50-2.40)\end{array}$ & 0.800 \\
\hline High & $\begin{array}{c}1.09 \\
(0.75-1.58)\end{array}$ & 0.620 & $\begin{array}{c}1.15 \\
(0.78-1.69)\end{array}$ & 0.403 & $\begin{array}{c}1.36 \\
(0.97-1.91)\end{array}$ & 0.068 & $\begin{array}{c}0.71 \\
(0.39-1.29)\end{array}$ & 0.271 & $\begin{array}{c}0.66 \\
(0.31-1.14)\end{array}$ & 0.292 \\
\hline
\end{tabular}

PR: prevalence ratio; Cl: confidence interval; B-FIS: Brazilian version of the Family Impact Scale; Values in bold type are significant at the 0.05 level.

\section{Discussion}

The study measured the impact of dental caries, parents' years of schooling, age, sex, and household income on the family's OHRQoL using the B-FIS in individuals with $\mathrm{SHCN}$. The FIS score ranged from 0 to 56, indicating that the measure allows for variations in the impact on the family's OHRQoL, and the total score ranged from 0 to 45 , indicating that the measure was sensitive to those variations. Adults with SHCN were included because there is a paucity of studies on OHRQoL in adulthood. These patients are referred to the ACOLHER-PNE project due to their poor access to oral health care after the age of 18 years. Few studies have been carried out with a representative sample that assesses the impact of dental caries on the quality of SHCN patients. ${ }^{7}$ Other studies have been conducted with specific populations, such as children with cerebral palsy, ${ }^{5}$ Down Syndrome, ${ }^{18}$ sickle cell disease (SCD) ${ }_{1}^{15}$ autism, ${ }^{16}$ and intellectual disability. ${ }^{4,6}$

Our study also showed that most caregivers of children with SHCN reported a negative impact on their OHRQoL. By analyzing the frequency of the B-FIS items, the most frequent impacts were "Have you or the other parent been upset?”, "Have you or the other parent worried that your child will have fewer life opportunities?," "Have you or the other parent felt guilty?," and "Has your sleep or that of the other parent been disrupted'?" These results are similar to the data shown in previous studies. ${ }^{15,21}$ Possibly, these items may be the most commonly cited ones because they affect sleep, school attendance, work opportunities, feeling guilty of son`s illness, in addition to requiring more time from caregivers, thereby causing a greater perceived impact on the family.

Studies have shown that dental caries had the greatest negative impact on the OHRQoL of subjects with and without disabilities. $5,7,15,16,18,20,21,22,23,24,25,26$ In the current study, caries experience was not associated with a greater negative impact on parents' QoL. However, the results demonstrated that caries experience (high and moderate) have a higher impact when compared to low caries experience and caries-free subjects in PE domains. Likewise, the level of dental caries (dmft/DMFT) may be described on the basis of categories of caries experience, but may not be an indicator of caries severity. It is recognized that oral diseases can have varying impacts on people and their well-being and quality of life. ${ }^{9-11}$ The impact observed 
in caries-free subjects was higher than that found in other studies. ${ }^{5,15}$ Therefore, the relation between high caries experience and negative impact on parents' QoL was not observed in this study as pointed out by other authors. ${ }^{5,15}$ However, more severe carious lesions were associated with a negative impact on the quality of life of preschool children. ${ }^{24,25,26}$

The relationship between sociodemographic characteristics and OHRQoL has been explored in several studies, but conflicting results have been found. Parents who had fewer years of schooling were more likely to rate their child's oral health worse than those who were more educated. ${ }^{5,25}$ On the other hand, psychosocial and socioeconomic variables were not statistically associated with worse OHRQoL in subjects with intellectual disability. ${ }^{4}$ According to Pani et al., ${ }^{16}$ maternal level of education positively influenced FIS. However, those authors did not report on the influence of educational level on specific FIS domains. Notwithstanding, caregivers at a greater socioeconomic disadvantage tended to report a lower impact on the quality of life of children with caries experience. ${ }^{26}$

This study had some limitations that need to be addressed. The use of a convenience sample increases the possibility of bias and the sample may thus be similar in many aspects. SHCN in the whole population may present different characteristics. The studied sample was deliberately limited to those referred to secondary health services, providing a sample of subjects with higher prevalence of potential risk factors for poor oral health than the general population. ${ }^{10}$ The present study did not evaluate the severity of the patients' general clinical status, but some previous studies did that, and a greater impact was then observed among patients with greater disease severity. ${ }^{5,15}$ The quality of life of these individuals is directly affected over time. ${ }^{4}$ In fact, in the current study, the overall B-FIS score was greater for neurological disorders, syndromes, and behavioral disorders, but no difference was found among individuals with $\mathrm{SHCN}$ regarding the impact on their families.

All domains were negatively affected in older individuals. These results may have occurred for two reasons. First, the lack of medical assistance and difficulties in government and family support may have a greater impact on these caregivers. ${ }^{11}$ Second, postponement or denial of care can result in pain, discomfort, increased treatment needs and costs, unfavorable treatment experiences, and some impact on the family's OHRQoL. ${ }^{9}$ In addition, the perception that their children need dental treatment may have a detrimental influence on COHRQoL. Also, it may be plausible that mothers who are not aware of the fact that their children need to see a dentist are less likely to perceive an impact on their children's OHRQoL. In addition, older individuals with $\mathrm{SHCN}$ have difficulty expressing their feelings and discomfort, which often creates a sense of uncertainty and frustration in their parents. Moreover, according to Fernandes et al., ${ }^{15}$ among the parents of younger children, dental caries and sickle cell disease severity significantly affected the subscales for parental activities (PA) and parental emotions (PE). However, among parents of adolescents, dental caries (DMFT) adversely affected PE and PA subscales. In this study with older subjects, the greater negative impact on parents' QoL was observed in family conflict and financial burden.

The present study underscores the importance of early identification of the factors that negatively impact the OHRQoL of children and adults with SHCN and of the implementation of preventive measures. Parents of children with SHCN might pay less attention to their oral health, considering the complexity of their conditions, but this may cause pain, discomfort, absence from work and school, poor nutrition due to sleepless nights, and problems with feeding. ${ }^{6}$

Further longitudinal studies are needed to assess the evaluative properties of the measure, and large samples of individuals from different locations are needed to confirm and extend the findings on family impact reported in our study.

\section{Conclusions}

Older children were associated with a worse impact on their parents' QoL. Higher caries experience, mother's years of schooling, household income, sex, and SHCN conditions were not associated with a negative impact on OHRQoL of individuals with SHCN. 
Individuals with special needs and their families' oral health-related quality of life

\section{References}

1. American Academy of Pediatric Dentistry. Guideline on management of dental patients with special healthcare needs. Pediatr Dent. 2012;37(6):166-71.

2. Faulks D, Norderyd J, Molina G, Macgiolla Phadraig C, Scagnet G, Eschevins $C$ et al. Using the International Classification of Functioning, Disability and Health (ICF) to describe children referred to special care or paediatric dental services. PLoS One. 2013 Apr;8(4):e61993. https://doi.org/10.1371/journal.pone.0061993

3. Faker K, Di Lanaro N, Paula VA, Tostes MA. Profile of special needs patients assisted in a dental project. Braz Dent Sci. 2016;19(4):14-20. https://doi.org/10.14295/bds.2016.v19i4.1300

4. Alves NS, Gavina VP, Cortellazzi KL, Antunes LA, Silveira FM, Assaf AV. Analysis of clinical, demographic, socioeconomic, and psychosocial determinants of quality of life of persons with intellectual disability: a crosssectional Study. Spec Care Dentist. 2016 Nov;36(6):307-14. https://doi.org/10.1111/scd.12196

5. Abanto J, Carvalho TS, Bönecker M, Ortega AO, Ciamponi AL, Raggio DP. Parental reports of the oral health-related quality of life of children with cerebral palsy. BMC Oral Health. 2012 Jun;12:15. https://doi.org/10.1186/1472-6831-12-15

6. Weckwerth SA, Weckwerth GM, Ferrairo BM, Chicrala GM, Ambrosio AM, Toyoshima GH et al. Parents' perception of dental caries in intellectually disabled children. Spec Care Dentist. 2016 Nov;36(6):300-6. https://doi.org/10.1111/scd.12191 PMID:27420288

7. Aggarwal VP, Mathur A, Dileep CL, Batra M, Makkar DK. Impact of sociodemographic attributes and dental caries on quality of life of intellectual disabled children using ECOHIS. Int J Health Sci (Qassim). 2016 Oct;10(4):480-90.

8. Cardoso AM, Gomes LN, Silva CR, Soares RS, Abreu MH, Padilha WW et al. Dental caries and periodontal disease in Brazilian children and adolescents with cerebral palsy. Int J Environ Res Public Health. 2014 Dec;12(1):335-53. https://doi.org/10.3390/ijerph120100335

9. Baiju RM, Peter E, Varghese NO, Sivaram R. Oral health and quality of life: current concepts. J Clin Diagn Res. 2017 Jun;11(6):ZE21-6. https://doi.org/0.7860/JCDR/2017/25866.10110

10. Sischo L, Broder HL. Oral health-related quality of life: what, why, how, and future implications. J Dent Res. 2011 Nov;90(11):1264-70. https://doi.org/10.1177/0022034511399918

11. Piovesan C, Marquezan M, Kramer PF, Bönecker M, Ardenghi TM. Socioeconomic and clinical factors associated with caregivers' perceptions of children's oral health in Brazil. Community Dent Oral Epidemiol. 2011 Jun;39(3):260-7. https://doi.org/10.1111/j.1600-0528.2010.00598.x
12. Locker D. Disparities in oral health-related quality of life in a population of Canadian children. Community Dent Oral Epidemiol. 2007 Oct;35(5):348-56. https://doi.org/10.1111/j.1600-0528.2006.00323.x

13. Barbosa TS, Gavião MB. Evaluation of the family impact scale for use in Brazil. J Appl Oral Sci. 2009 Sep-Oct;17(5):397-403. https://doi.org/10.1590/S1678-77572009000500009

14. Goursand D, Paiva SM, Zarzar PM, Pordeus IA, Allison PJ. Family Impact Scale (FIS): psychometric properties of the Brazilian Portuguese language version. Eur J Paediatr Dent. 2009 Sep;10(3):141-6.

15. Fernandes ML, Kawachi I, Corrêa-Faria P, Paiva SM, Pordeus IA. The impact of the oral condition of children with sickle cell disease on family quality of life. Braz Oral Res. 2016;30(1):18. https://doi.org/10.1590/1807-3107BOR-2016.vol30.0021

16. Pani SC, Mubaraki SA, Ahmed YT, Alturki RY, Almahfouz SF. Parental perceptions of the oral healthrelated quality of life of autistic children in Saudi Arabia. Spec Care Dentist. 2013 Jan-Feb;33(1):8-12. https://doi.org/10.1111/j.1754-4505.2012.00294.x

17. Instituto Brasileiro de Geografia e Estatística. Censo demográfico 2010. Rio de Janeiro: Instituto Brasileiro de Geografia e Estatística; 2010 [citado 2017 apr 4]. Available from: http://www.ibge.gov.br/home/estatistica/populacao/ censo2010/default.shtm

18. Bonanato K, Pordeus IA, Compart T, Oliveira AC, Allison PJ, Paiva SM. Cross-cultural adaptation and validation of a Brazilian version of an instrument to assess impairments related to oral functioning of people with Down syndrome. Health Qual Life Outcomes. 2013 Jan;11(1):4. https://doi.org/10.1186/1477-7525-11-4

19. World Health Organization. Oral health surveys, basic methods. 5th ed. Geneva: Word Health Organization; 2013.

20. Abanto J, Paiva SM, Raggio DP, Celiberti P, Aldrigui $J M$, Bönecker M. The impact of dental caries and trauma in children on family quality of life. Community Dent Oral Epidemiol. 2012 Aug;40(4):323-31. https://doi.org/10.1111/j.1600-0528.2012.00672.x

21. Corrêa-Faria P, Paiva SM, Pordeus IA, Ramos-Jorge ML. Influence of clinical and socioeconomic indicators on dental trauma in preschool children. Braz Oral Res. 2015;29(1):1-7. https://doi.org/10.1590/1807-3107BOR-2015.vol29.0015

22. Bendo CB, Paiva SM, Abreu MH, Figueiredo LD, Vale MP. Impact of traumatic dental injuries among adolescents on family's quality of life: a population-based study. Int J Paediatr Dent. 2014 Sep;24(5):387-96. https://doi.org/10.1111/ipd.12083

23. Firmino RT, Gomes MC, Vieira-Andrade RG, Martins CC, Paiva SM, Granville-Garcia AF. Case-control study examining the impact of oral health problems on the quality of life of the families of preschoolers. Braz Oral Res. 2016 Nov;30(1):e121. https://doi.org/10.1590/1807-3107bor-2016.vol30.0121 
24. Ramos-Jorge J, Alencar BM, Pordeus IA, Soares ME, Marques LS, Ramos-Jorge ML et al. Impact of dental caries on quality of life among preschool children: emphasis on the type of tooth and stages of progression. Eur J Oral Sci. 2015 Apr;123(2):88-95. https://doi.org/10.1111/eos.12166

25. Guedes RS, Ardenghi TM, Piovesan C, Emmanuelli B, Mendes FM. Influence of initial caries lesions on quality of life in preschool children: a 2-year cohort study. Community Dent Oral Epidemiol. 2016 Jun;44(3):292-300. https://doi.org/10.1111/cdoe.12217

26. Chaffee BW, Rodrigues PH, Kramer PF, Vítolo MR,

Feldens CA. Oral health-related quality-of-life scores differ by socioeconomic status and caries experience.

Community Dent Oral Epidemiol. 2017 Jun;45(3):216-24 https://doi.org/10.1111/cdoe.12279 